\title{
Cross-reacting surface proteins between different Escherichia coli 0157:H7 strains and their immune responses in animal models
}

\author{
Ashikun Nabi ${ }^{1,2}$, Fatema Moni Chowdhury ${ }^{1,3}$, Zeenat Jahan ${ }^{1,4}$, Md Murshed Hasan Sarkar ${ }^{1,5}$, Fazle Rabbi ${ }^{1}$, \\ Chowdhury Rafiqul Ahsan ${ }^{1 *}$ \\ ${ }^{I}$ Department of Microbiology, University of Dhaka, Dhaka 1000, Bangladesh; ${ }^{2}$ Department of Molecular, Cellular and Developmental Biology, Yale University, \\ 219 Prospect St, New Haven, CT 06511, USA; ${ }^{3}$ Department of Microbiology, Jagannath University, 9-10 Chittaranjan Road, Dhaka 1100, Bangladesh; ${ }^{4}$ Garvan \\ Institute of Medical Research, Darlinghurst, New South Wales, Australia; ${ }^{5}$ Bangladesh Council of Scientific and Industrial Research, Rajshahi, Bangladesh
}

\begin{abstract}
Surface proteins of Escherichia coli $\mathrm{O} 157: \mathrm{H} 7$, those that are prominent in antigen-antibody reactions among different strains, were found to provide protection against $E$. coli 0157 challenge in mice. Three strains such as $E$. coli 0157:H7 NCTC reference strain and two other environmentally isolated strains have been used in this study. New Zealand rabbits were immunized with surface proteins of NCTC reference strain and immunoblot analysis was performed against the surface proteins of all three strains. Immunoblot analysis revealed that a $94 \mathrm{kDa}$ surface protein of $E$. coli $0157: \mathrm{H} 7$ could be the possible candidate for the protective activity experiment. Group of mice receiving the $94 \mathrm{kDa}$ surface protein through both intraperitoneal and intranasal routes survived the challenge experiment. Whereas, all the control mice died within a couple of days. Mice challenge experiment clearly demonstrated the strong potential of the $94 \mathrm{kDa}$ protein in the immunized mice. The data of this study provide us with a basis for further characterization of $94 \mathrm{kDa}$ surface protein of $E$. coli $0157: \mathrm{H} 7$ as a protective antigen.
\end{abstract}

Keywords: Surface protein, E. coli 0157:H7, Immune response

\section{Introduction}

Enterohemorrhagic Escherichia. coli $\mathrm{O} 157: \mathrm{H} 7$ is one of the significant causes of food and waterborne illness in the developed nations across the globe. Transmission of the disease mainly occurs via the consumption of contaminated food, water and person to persontransmission ${ }^{1}$. Clinical spectrum of the disease includes watery diarrhea, bloody diarrhea, hemorrhagic colitis and life-threatening hemolytic uremic syndrome (HUS), which may develop in the people of all age groups.

The pathogenesis of E. coli $\mathrm{O} 157: \mathrm{H} 7$ disease is multifactorial and involves several levels of interaction between the bacterium and the host. These include colonization of gut, generation of diarrhea and intestinal lesions, where two different types of Shiga toxins interact with host tissues. The major virulence factor and a defining characteristic of EHEC, is the production of Shiga toxin and the formation of $\mathrm{A} / \mathrm{E}$ lesions, which may lead to death and other symptoms in patients infected with EHEC ${ }^{2}$. Apart from these virulence factors, intimin, which is a $94 \mathrm{kDa}$ to $97 \mathrm{kDa}$ outer membrane protein encoded by eae (which stands for E. coli attaching and effacing), is considered as an adherence factor that has been demonstrated to play a role in intestinal colonization in vivo in an animal model ${ }^{3}$. These strains produce extensive $\mathrm{A} / \mathrm{E}$ lesions in the large intestine, featuring intimate adherence of the bacteria to the epithelial cells. On the other hand, the E. coli O157:H7 strains with mutation in the eae gene, could no longer produce $\mathrm{A} / \mathrm{E}$ lesions and indeed, did not appear to colonize any intestinal site ${ }^{2}$. Along with intimin, other surface proteins of $E$. coli $\mathrm{O} 157$ strains (Tir and components of type III secretion systems) are believed to play important roles in the colonization of bacteria in the gut. Cross-reactivity of E. coli O157 LPS with other enteric pathogens has been previously reported ${ }^{4}$. Also, the outermembrane proteins, which play important role in pathogenesis have shown cross-reactivity with other Gram-negative enteric pathogens ${ }^{5}$. In continuation to these previous findings, it would be very interesting to investigate the common or cross-reacting surface proteins among different strains of E. coli $\mathrm{O} 157$ (including clinical and environmental strains) and their pathogenic properties as well as immune response in animal models.

In this study we tried to demonstrate various cross reacting surface proteins of different $E$. coli $\mathrm{O} 157: \mathrm{H} 7$ strains and the immune responses induced by these surface proteins in protecting animals against live cell challenge.

\section{Materials and Methods}

\section{Bacterial strains}

The E. coli O157:H7 (NCTC strain Ref. no. 12079) and two locally isolated environmental E. coli $\mathrm{O} 157: \mathrm{H}$ strains $^{5}$, were all obtained from Department of Microbiology, University of Dhaka.

\section{Animal maintenance}

New Zealand white rabbits (1.5-2 kg body weight) and Swiss albino mice (5-7 weeks old) were obtained from the Animal Division of International Centre for Diarrheal Disease Research, 
Bangladesh (icddr,b). The mice were randomly selected and kept in plastic cages with wood-cobe bedding. After five days of acclimation, the animals were divided into different groups for the experiments. All the experiments and procedures using these animals were undertaken following the ethical issues set by the Faculty of Biological Sciences, University of Dhaka, Bangladesh.

\section{Preparation of water extracted materials (WEM)}

Bacterial strains (NCTC strain and other two E. coli O157:H7 strains) were grown in Brain Heart Infusion broth medium (500 $\mathrm{ml}$ ) for overnight at $37^{\circ} \mathrm{C}$ in a shaker incubator. Cells were harvested by centrifugation, washed with normal saline $(0.85 \%$ $\mathrm{NaCl}$ solution) for three times. The washed pellet was then resuspended in around 5-7 $\mathrm{ml}$ of autoclaved distilled water and the mixture was placed in room temperature shaker for $6 \mathrm{~h}$. Finally, the mixture was centrifuged at $12000 \times \mathrm{g}$ for $15 \mathrm{~min}$. Supernatant was then filtered through the $0.45 \mu \mathrm{m}$ milipore membrane filter and stored at $-20^{\circ} \mathrm{C}$ until use. The amount of protein in the WEM was estimated by Bio-Rad protein assay. The same lot of WEM from NCTC 12079 and other two environmental strains was used throughout the whole study.

\section{Immunization of rabbits and serum collection}

Four New Zealand white rabbits were immunized with prepared WEM of NCTC strain, containing surface proteins at a ratio of $50 \mu \mathrm{g}$ per kg body weight. Water extracted materials were injected with incomplete and complete adjuvant via intramuscular route. Sera collected before immunization was served as preimmunized control sera. The rabbits were immunized with two doses of WEM at 15 days intervals and sacrificed 7 days after administering final booster dose. Serum was collected at 7 days intervals to measure the antibody titer.

\section{Enzyme Linked Immunosorbent Assay (ELISA)}

An ELISA method was used to quantitate serum antibody recognizing $E$. coli $\mathrm{O} 157: \mathrm{H} 7$ surface proteins preparation and to determine the cross-reactivity among the surface proteins of different $E$.coli $\mathrm{O} 157: \mathrm{H} 7$ clinical and environmental strains ${ }^{6}$. In brief, WEM of different strains (NCTC 12079 and two other environmental strains) was used as antigens. Flat bottom polystyrene plate was coated with diluted WEM $(1 \mu \mathrm{g}$ of surface protein to each well) in bicarbonate coating buffer ( $\mathrm{pH} 9.6)$ and $100 \mu 1$ of rabbit serum, serially diluted in $0.5 \%$ BSA (w/v) in PBS, were added to each well. After incubation and washing four times, $100 \mu$ l of alkaline-phosphatase conjugated anti-rabbit IgG (diluted 1:1000) were added to each well and the plate was incubated for further $2 \mathrm{~h}$ at room temperature. After final washing, $100 \mu 1$ of Á-nitrophenylphosphate disodium salt $(1 \mathrm{mg} / \mathrm{ml})$ in glycine buffer ( $\mathrm{pH} 9.5$ ) was added to each well. Reaction was stopped by adding $25 \mu \mathrm{l}$ of $3 \mathrm{M} \mathrm{NaOH}$ and the absorbance was measured at $405 \mathrm{~nm}$ in micro-ELISA reader.

Gel electrophoresis and immunoblot analysis

Gels consisting of 5\% (w/v) acrylamide-stacking gel and $12.5 \%$ $(\mathrm{w} / \mathrm{v})$ acrylamide-separation gel in a discontinuous polyacrylamide gel electrophoresis (PAGE) system with Laemmli buffers were used for the separation of different surface proteins ${ }^{7}$. Electrophoresis was performed using the mini-protean III system (Bio-Rad Laboratories Ltd., Richmond, Calif.) with a current of $12 \mathrm{~mA}$ for first $12-15 \mathrm{~min}$ then $15 \mathrm{~mA}$ for $1 \mathrm{~h}$. Presence of different surface proteins was visualized by coomassie blue staining. For immunoblotting, instead of staining with coomassie blue, separated surface proteins in the gels were transferred onto nitrocellulose paper following the method described by Laemmli ${ }^{8}$. Primary antibody of rabbit sera was added in 1:100 dilutions for $1.5 \mathrm{~h}$ at room temperature after blocking the strip with $3 \%$ skim milk in PBS. Strips were then washed with $0.1 \%$ Tween 20 in PBS for three times. Secondary antibody (alkaline phosphatase conjugated goat anti-rabbit antibody, whole molecule, Sigma, USA) in 3\% skim milk at 1:10000 dilutions were added for $1.5 \mathrm{~h}$ at room temperature. After final washing as stated above, blot strips were placed in substrate solution (containing $0.1 \mathrm{M}$ Tris$\mathrm{HCl}$ solution, $0.09 \mathrm{M} \mathrm{NaCl}$ solution, $0.15 \mathrm{M} \mathrm{MgCl}_{2}$, BCIP, NBT) until the bands had appeared. Molecular weight of different surface proteins reacted with immunized rabbit (WEM of NCTC) sera was determined by calculating the relative mobility $\left(\mathrm{R}_{\mathrm{f}}\right)$ value of the standard marker proteins.

Separation of the specific surface proteins from number of protein mixture in WEM

A $10 \%$ separating gel was made in combination with a $5 \%$ stacking gel and approximately $300 \mu \mathrm{l}$ of WEM of different $E$. coli $\mathrm{O} 157: \mathrm{H} 7$ strains were loaded on the gel. The separated proteins in gel were transferred to nitrocellulose membrane. The membrane was washed with $0.1 \%$ Amido black stain to locate the position of protein bands. The membrane was cut carefully and subjected to immunoblot analysis to locate the position of different proteins that gave immune reaction with antisera raised in rabbits immunized with the WEM of NCTC strain. Membrane was cut and placed into PBS after locating the position of the protein and were sonicated until the membrane reduced to fine powder form to pass through a 25 -gauge hypodermic needle ${ }^{9}$.

\section{Immunization of mice}

To demonstrate the protective efficacy of the different surface proteins in mice, a group of sixteen Swiss albino mice were used in each group. Each mouse was administrated with certain molecular weight of surface proteins $(20-25 \mu \mathrm{g}$ protein/mice) via intraperitoneal or intranasal route at 15 days intervals. Sera were taken at 7 days intervals and 30 days after last immunization and titer of antibodies was checked in the pooled sera by the ELISA. Immunoblot analysis was also used to check the homogeneity of the separated surface proteins. Groups of 16 mice in case of both intraperitoneal and intranasal route were used as negative controls receiving only sonicated nitrocellulose membrane (same turbidity as the experimental sonicated membrane) in PBS buffer. 
Determination of $50 \%$ Lethal Dose $\left(L D_{50}\right)$ of E. coli O157:H7 (NCTC, Ref no. 12079) and challenge experiment

$\mathrm{LD}_{50}$ dose was determined by the method described by Boyd ${ }^{10}$, where each group of Swiss albino mice was administered with $100 \mu 1$ of bacterial suspension (E. coli O157:H7 NCTC, Ref. no. 12079) containing $10^{6}, 10^{7}$ and $10^{8} \mathrm{CFU} / \mathrm{ml}$ live cells through intraperitoneal route. For the challenge experiment, 16 mice (67 weeks old) were included in each group, where immunized mice were challenged with the $\mathrm{LD}_{50}$ dose of the organism. Death of mice were recorded daily for 21 days and all mice alive after 21 days were considered to have survived the challenge ${ }^{11}$.

\section{Results}

Surface proteins that are recognized among different strains of E. coli O157:H7

WEM containing the surface proteins of NCTC strain and other two environmentally isolated E. coli $\mathrm{O} 157: \mathrm{H} 7$ strains were analyzed by gel electrophoresis. All three strains showed almost similar surface proteins profile characterized by the presence of some common protein bands (data not shown).

Antiserum raised in rabbits against the surface proteins of NCTC strain was applied to perform the immunoblots against the surface proteins of all three strains. The antiserum recognized several surface proteins such as $143 \mathrm{kDa}, 94 \mathrm{kDa}$ and $58 \mathrm{kDa}$ in case of all three strains. But one protein band of approximately $94 \mathrm{kDa}$ showed the most outstanding reaction in case of all three strains in terms of color and intensity. Analysis of immunoblot result revealed surface proteins of approximately $94 \mathrm{kDa}$ and $143 \mathrm{kDa}$ could have the aptitude to evaluate the protective efficacy against live challenge of NCTC strain.

Development course of the surface proteins specific antibodies in animal model

ELISA was performed to monitor the progress of surface proteins specific antibodies after administration in animal model. In rabbit model, surface proteins specific antibody titers began to develop at $15^{\text {th }}$ day, attained the peak at $35^{\text {th }}$ day and sustained the same level of antibody titers at $45^{\text {th }}$ day as compared to preimmunized sera. Interestingly we observed same pattern of antibody response development when mice administrated with separated $94 \mathrm{kDa}$ and $143 \mathrm{kDa}$ surface protein both in intraperitoneal and intranasal route as compared with the rabbit sera but these two proteins varied in their ability to develop antibody titer in mice (Fig. 1).

\section{Mouse challenge experiment}

The $\mathrm{LD}_{50}$ dose for the organism was $100 \mu \mathrm{l}$ of live bacterial suspension containing $10^{8} \mathrm{CFU} / \mathrm{ml}$ in Swiss albino mice model. Different groups of mice were challenged with the $\mathrm{LD}_{50}$ dose of NCTC strain after the completion of the immunization protocol following intraperitoneal and intranasal route.

The deaths of mice were recorded daily two times for 21 days. Much difference was observed in the survival time among the groups receiving different surface proteins and the control group mice $(p<0.001)$. The most outstanding observation was that the group of mice receiving the $94 \mathrm{kDa}$ surface protein

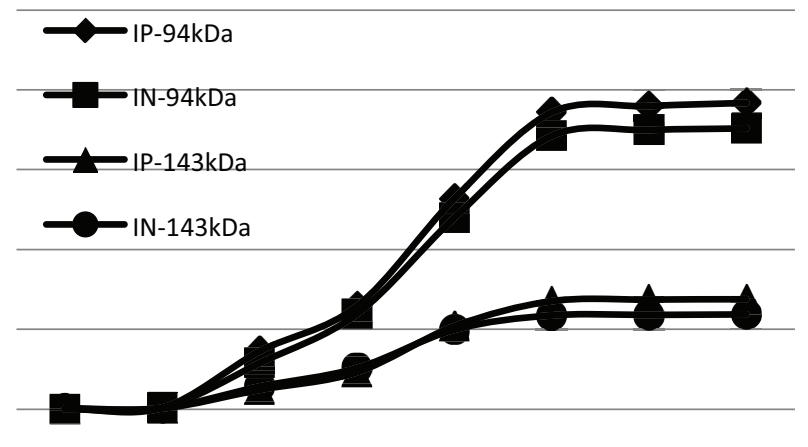

Figure 1. Development of surface protein specific antibody after immunization. Both the $94 \mathrm{kDa}$ and $143 \mathrm{kDa}$ surface proteins showed similar pattern of antibody development in case of intraperitoneal and intranasal routes but the titer of antibody against $94 \mathrm{kDa}$ surface protein showed much better result than the $143 \mathrm{kDa}$ surface protein.

intraperitoneally survived the challenge for 21 days and remained healthy. On the other hand, $50 \%$ of the control group of mice receiving only nitrocellulose membrane in PBS, died within 48 $\mathrm{h}$ after challenge with $\mathrm{LD}_{50}$ dose. Group of mice receiving 94 $\mathrm{kDa}$ surface protein via intranasal route also showed similar result after challenge experiment. Other groups including mice receiving $143 \mathrm{kDa}$ surface protein through the intranasal and intraperitoneal route, died within 5 days. To reveal whether antibodies against $94 \mathrm{kDa}$ surface protein provide the protection in the survived group, sera of unchallenged mice were subjected to immunoblot analysis against the WEM of NCTC strain. Result of immunoblot analysis (Fig. 3 and Fig. 4) clearly demonstrated that the survived

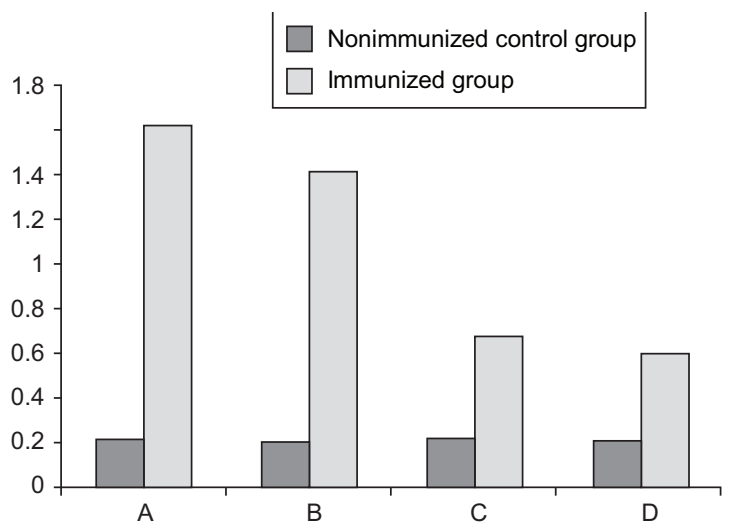

Figure 2. Comparison of antibody response between immunized and nonimmunized group. In the figure A shows the comparison of antibody titer between nonimmunized and immunized mice group receiving $94 \mathrm{kDa}$ surface protein through intraperitonial route, $B$ shows the comparison of antibody titer between nonimmunized and immunized mice group receiving $94 \mathrm{kDa}$ surface protein through intranasal route, C shows the comparison of antibody titer between nonimmunized and immunized mice group receiving $143 \mathrm{kDa}$ surface protein through intraperitonial route, $D$ shows the comparison of antibody titer between nonimmunized and immunized mice group receiving $143 \mathrm{kDa}$ surface protein through intranasal route. 


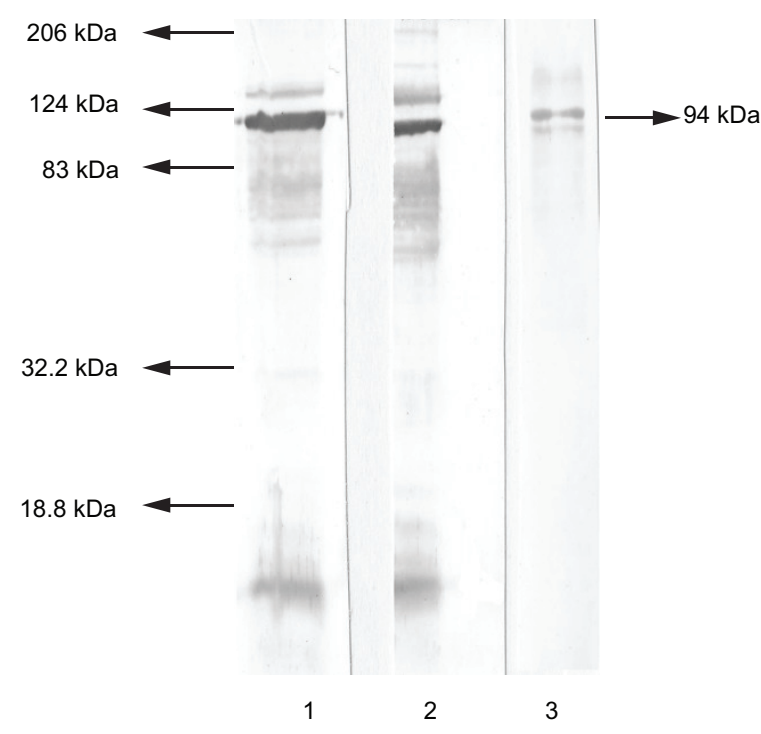

Figure 3. Western blot analysis of surface proteins of different strains of E. coli O157:H7. Lane 1, locally isolated strain-1; Lane 2, NCTC strain; Lane 3, locally isolated strain-2. All the strains have a common protein band of $94 \mathrm{kDa}$ which showed most prominent immunogenic reaction.

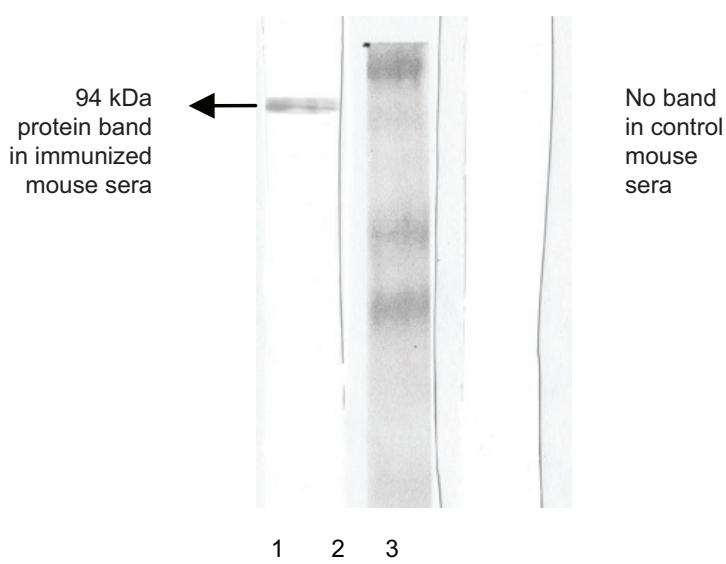

Figure 4. Western Blot analysis with mouse sera. Lane 1, 94 kDa immunized mouse serum; Lane 2, Marker; Lane 3, Control mouse serum immunized with only nitrocellulose membrane in $P B S$.

Table 1. The survival of mice after immunization.

\begin{tabular}{|c|c|c|c|c|c|c|c|}
\hline Group & $\begin{array}{c}\text { Total } \\
\text { mice }(\mathrm{n})\end{array}$ & 1 day & 2 days & 3 days & 4-21 days & $\begin{array}{c}\text { No of } \\
\text { surviving } \\
\text { mice }\end{array}$ & $\begin{array}{c}\text { Protection } \\
\text { rate }(\%)\end{array}$ \\
\hline Intraperitonial immunization with $143 \mathrm{kDa}$ surface protein & 16 & 3 & 2 & 0 & 0 & 11 & 68 \\
\hline Intraperitonial control group & 16 & 6 & 2 & 0 & 0 & 8 & 50 \\
\hline Intranasal immunization with $143 \mathrm{kDa}$ surface protein & 16 & 2 & 4 & 0 & 0 & 10 & 62.5 \\
\hline Intraperitonial control group & 16 & 7 & 1 & 0 & 0 & 8 & 50 \\
\hline
\end{tabular}

group of mice exclusively comprised the antibodies against 94 $\mathrm{kDa}$ protein which also indicated that protection was solely provided by these antibodies since no other antibodies were detected in the control group mice that received only PBS containing nitrocellulose membrane. Presence of single band in immunoblot assay also indicated the fact that contamination with other surface proteins did not occur during protein separation and immunization.

\section{Discussion}

Infection caused by $E$. coli $\mathrm{O} 157: \mathrm{H} 7$ has become a global public health problem because of its severity and subsequent development of HUS. Although antibiotics are still the most effective treatment procedure against $\mathrm{O} 157$ infection but the use of some antibiotics facilitate the increased production of Stx toxin which play the vital role in the development of $\mathrm{HUS}^{12,13}$. Under these circumstances vaccination is one of the most promising ways of combating against $E$. coli $\mathrm{O} 157$ infection. However, there is no effective vaccine available for clinical use that can provide sustained, broad-based protection. Moreover, whole bacterial vaccines can cause side effects because of complex antigens $E$. coli of O157:H7.

The present study has investigated the surface proteins among clinical strain (NCTC strain) and environmentally isolated strain of $E$. coli $\mathrm{O} 157 \mathrm{H} 7$ from cattle source. We have selected these strains to assess if the clinical strain and the environmental strain have some common surface proteins that contribute to immune reaction in rabbit model. The hypothesis lying behind this type of selection is that, if both the clinical and environmental strains haveshared epitopes, incorporation of these surface proteins in the subunit vaccine will provide the protection against the $E$. coli $\mathrm{O} 157: \mathrm{H} 7$ strains prevalent in the food chain and the 
environment, as well as in case of strains involved in human to human transmission. Rabbit model immunization data showed surface proteins of $57 \mathrm{kDa}, 94 \mathrm{kDa}$ and $143 \mathrm{kDa}$ were present in all three stains but $198 \mathrm{kDa}, 63 \mathrm{kDa}$ and some other surface proteins of certain molecular weight were exclusively present in only NCTC strain, but not in the environmental strain indicating surface proteins of different $E$. coli $\mathrm{O} 157: \mathrm{H} 7$ differ significantly in their immunogenic reactions (Fig. 3). Immunoblot with immunized rabbit sera result has also suggested common surface proteins of $94 \mathrm{kDa}$ and $143 \mathrm{kDa}$ have the aptitude to play role in protective function in mice model.

For the development of a successful vaccine two important facts that should be considered are the choice of candidate immunogen and route of immunization ${ }^{14}$. In this study, we have included 94 $\mathrm{kDa}$ and $143 \mathrm{kDa}$ surface proteins separately as immunogens and intraperitoneal and intranasal routes as a way of immunization. Immunization of mice with both the surface proteins has elicited IgG antibody response as compared with the control group mice. However, the groups of mice receiving $94 \mathrm{kDa}$ surface protein through intraperitoneal and intranasal routes have demonstrated better response than the groups of mice receiving $143 \mathrm{kDa}$ surface protein (both intraperitoneal and intranasal route, Fig. 2). Data of ELISA and immunoblot analysis after immunization has been later supported by the mice challenge experiment with live $E$. coli $\mathrm{O} 157: \mathrm{H} 7$ strain, where the group of mice receiving $94 \mathrm{kDa}$ protein through intraperitoneal or intranasal route, has survived for 21 days where as nonimmunized control group died. The protection rate of intraperitoneal and intranasal group immunized with $94 \mathrm{kDa}$ protein is $93 \%$ and $87 \%$ respectively, which is highly significant ( $p \hat{\mathrm{A}} 0.05)$, whereas in case of $143 \mathrm{kDa}$ protein it is $68 \%$ and $62.5 \%$ respectively (Table. 1). Absence of contamination with other surface proteins in immunized group and IgG antibodies against $94 \mathrm{kDa}$ surface protein in control non-immunized group but the presence of this particular surface protein specific $\mathrm{IgG}$ antibody in immunized group, as has been checked by immunoblot, clearly demonstrate that the protection is provided by the $94 \mathrm{kDa}$ specific IgG antibody (Fig. 4).

\section{References}

1. Gyles CL. 2007. Shiga toxin-producing Escherichia coli: an overview. J Anim Sci. 85: E45-62. https://doi.org/10.2527/jas.2006-508.

2. Pacheco AR and Sperandio V. 2012. Shiga toxin in enterohemorrhagic $E$. coli: regulation and novel anti-virulence strategies. Front Cell Infect Microbiol. 2: 81. https://doi.org/10.3389/fcimb.2012.00081.

3. Donnenberg MS and Kaper JB. 1993. The role of the eae gene of enterohemorrhagic Escherichia coli intimate attachment in vitro and in a porcine model. J Clin Invest. 92: 1418-1424.

4. Navarro A, Eslava C, Hernandez U, Navarro-Henze JL, Aviles M, Garciade la Torre G and Cravioto A. 2003. Antibody Responses to Escherichia coli $\mathrm{O} 157$ and Other lipopolysaccharides in healthy children and adults. Clin Diagn Lab Immunol. 10(5): 797-801.

5. Rabbi F, Yasmin M, Nessa J, Nabi A, Chowdhury FM, Otomo Y and Ahsan CR. 2014. Bovine Escherichia coli O157:H7 of Bangladesh: Is it capable of causing diseases similar to clinical strains? African J Microbiol Res. 8(2): 147-154.

6. Torres AG, Li Y, Tutt CB, Xin L. Eaves-Pyles T and Soong L. 2006. Outer membrane protein A of Escherichia coli O157:H7 stimulates dendritic cell activation. Infect Immun. 74(5): 2676-2685.

7. Mel DM, Arsic BL, Nikolic BD and Radovanic ML. 1968. Studies on vaccination against bacillary dysentery. 4 . Oral immunization with live monotypic and combined vaccines. Bull World Health Organ. 39(3): 375-380.

8. Laemmli UK. 1970. Cleavage of structural proteins during the assembly of the head of bacteriophage T4. Nature. 227: 680-685.

9. Towbin H, Staehelin T and Gordon J. 1979. Electrophoretic transfer of protein from polyacrylamide gels to nitrocellulose sheets: procedure and some applications. Proc. NatIAcad. Sci. USA. 76: 4350-4354.

10. Diano M, Bivie AL and Hira M. 1987. A method for the production of highly specific polyclonal antibodies. Analytical Biochem. 166: 224-229.

11. Boyd WC. 1966. Fundamentals of immunology, $4^{\text {th }}$ edition, p773. Interscience Publishers, New York.

12. Briles DE, Crain MJ, Gray BM, Forman C and Yother J. 1992. Strong association between capsular type and virulence for mice among human isolates of Streptococcus pneumoniae. Infect. Immune. 60: 111-116.

13. Safdar N, Said A, Gangnon RE and Maki DG. 2002. Risk of hemolytic uremic syndrome after antibiotic treatment of Escherichia coli O157:H7 enteritis. JAMA. 288(8): 996-1001.

14. Wong CS, Jelacic S, Habeeb RL, Watkins SL and Tarr PI. 2000. The risk of the hemolytic-uremic syndrome after antibiotic treatment of Escherichia coli O157:H7 infections. N. Engl. J. Med. 342: 1930-1936.

15. Fan HY, Wang L, Luo J and Long BG. 2012. Protection against Escherichia coli $\mathrm{O} 157: \mathrm{H} 7$ challenge by immunization of mice with purified Tir proteins. Mol. Biol. Rep. 39: 989-997. 